\title{
Do rascunho à edição: análise preliminar das versões de "The Sicilian Tale: King Robert of Sicily" por D. Pedro II
}

Adriano Mafra ${ }^{1}$

\section{Introdução}

O PRESENTE ESTUDO OBJETIVA APRESENTAR UMA ANÁLISE PRELIMINAR DOS MANUSCRITOS AUTÓGRAFOS DA TRADUÇÃO EMPREENDIDA PELO IMPERADOR D. PEDRO II de um poema de Henry W. Longfellow do inglês para o português. Os manuscritos constituem a fase final de duas campanhas de escrituras distintas, com um hiato temporal de mais de duas décadas entre elas: a primeira é de meados de 1860, que originou pelo menos duas cópias e uma publicação; e a outra de fins da década de 1880. Esses documentos encontram-se arquivados em duas instituições do estado do Rio de Janeiro. Seguindo as pesquisas desenvolvidas pelos pesquisadores do Núcleo de Estudos em Processos Criativos (NUPROC/ UFSC) sobre o labor tradutório e produção intelectual do segundo imperador brasileiro, o artigo respalda-se no aporte metodológico da Crítica Genética ${ }^{2}$ para investigar os documentos autógrafos em um viés de análise sociológica da tradução ${ }^{3}$. Se traduzir passa a ser uma atividade mediada por normas históricas e culturais, a seleção dos textos, as escolhas interpretativas, a divulgação, a recepção e a avaliação das traduções passam a ser, então, fortemente influenciadas pelo contexto sociocultural em que foram escritos. O tradutor, no processo de escrita, "manipula" o texto fonte, moldando-o aos valores e interesses da sociedade em que está inserido, mesmo que esses valores, por vezes, não lhe sejam percebidos conscientemente. Nas traduções de D. Pedro II, a chamada "manipulação" do texto servirá, em grande medida, para trazer subjacentemente um plano político de construção de uma identidade nacional brasileira autônoma no cenário mundial do final do século XIX. Essa constituição de uma identidade nacional brasileira (e política, por consequência) desenvolveu-se a partir da incansável e quase obsessiva política cultural do monarca centrada na

\footnotetext{
1 Doutor em Estudos da Tradução pela Universidade Federal de Santa Catarina e em Translation Science pela University of Antwerp (Bélgica). Professor da Educação Básica, Técnica e Tecnológica no Instituto Federal Catarinense - Campus Ibirama e pesquisador do Núcleo de Estudo de Processos Criativos (NUPROC/DLLE/UFSC). E-mail: adriano.mafra@ifc.edu.br

${ }^{2}$ BELLEMIN-NoËL, Jean. Reproduzir o manuscrito, apresentar os rascunhos, estabelecer um prototexto. Manuscrítica: Revista de Crítica Genética. São Paulo, APML, n. 4, 1993, p. 127-161; BIASI, Pierre-Marc de. A crítica genética. In: BERGEZ, Daniel et al. Métodos críticos para a análise literária. Tradução Olinda Maria Rodrigues Prata. São Paulo: Martins Fontes, 1997; BIASI, Pierre-Marc de. A genética dos textos. Tradução Marie-Hélène Paret Passos. Porto Alegre: EDIPUCRS, 2010; GRÉSILlON, Almuth. Elementos de crítica genética: ler os manuscritos modernos. Supervisão da tradução Reulliard. Porto Alegre: Editora UFRGS, 2007; WILlERMART, Philippe. Universo da criação literária: crítica genética, crítica pós-moderna? São Paulo: Edusp, 1993, entre outros.

${ }^{3}$ TourY, Gideon. Descriptive Translation Studies and Beyond. Amsterdam; Philadelphia: John Benjamins Publishing Company, 1995; LAMBerT, José; GORP, Hendrik van. On describing translations. In: Hermans, Theo. (Ed.). The Manipulation of Literature. Studies in Literary Translation. London \& Sidney, Croom Helm, 1985, p. 42-53; EvEN-ZOAR, Itamar. Polysystem Theory. Poetics Today. International Journal for Teory and Analysis of Literature and Communication, v. 11. n. 1, Spring 1990; FAIQ, Said. The cultural salad in/of translation. In: FAIQ, Said (Ed.). Cultures in Dialogue: a translational perspective. Antwerp; Apeldoorn: Garant, 2010, p. 13-22; GENTZLER, Edwin. Teorias contemporâneas da tradução. Tradução Marcos Malvezzi. São Paulo: Madras, 2009; HeRmANS, Theo. Translation in Systems: Descriptive and System oriented Approaches Explained. Manchester: St. Jerome Publishing, 1999; e LEFEVERE, André. Translation, Rewriting $\mathcal{E}$ the Manipulation of Literary Fame. London: Routledge, 1992.
} 
escrita, na tradução e na educação ${ }^{4}$. A tradução do poema de Longfellow, neste caso, configura-se também como um importante veículo de trocas culturais internacionais entre a corte brasileira - um polissistema periférico - e o centro cultural e intelectual americano do século XIX - detentor de repertório cultural e literário mais prestigiado.

Partindo da transcrição diplomática dos manuscritos, algumas características do texto de partida são evidenciadas nesta primeira análise, como o conteúdo e os aspectos formais da obra de Longfellow. A relação entre o tradutor Pedro d'Alcântara e o autor do texto de partida também é abordada, pois acredita-se que essa conexão, além de fornecer indícios para que compreendamos os contextos histórico e cultural que circunscrevem os manuscritos, também constitui um primeiro indicativo da anglofilia em D. Pedro II. Ademais, ao investigar a relação do monarca com outros literatos e intelectuais atuantes nos Estados Unidos a partir da década de 1850, é possível entender também de que maneira essas interações influenciaram o acesso, a produção e a circulação da obra analisada e das traduções realizadas por Pedro II naquele período. A tradução, nesse processo, foi o meio escolhido por D. Pedro para inicialmente acessar e interagir com parte da elite intelectual norte-americana dos oitocentos.

\section{Os manuscritos: dois projetos de tradução}

Os manuscritos da tradução da obra de Longfellow operada pelo monarca encontram-se armazenados em duas instituições. A cópia utilizada na publicação de 1889 faz parte do acervo do Arquivo Histórico do Museu Imperial de Petrópolis (MIMP), enquanto as outras duas estão arquivadas no Instituto Histórico e Geográfico Brasileiro (IHGB), na cidade do Rio de Janeiro.

São oito páginas manuscritas arquivadas no Museu Imperial. De modo geral, os manuscritos receberam a lápis a indicação do número do documento (Doc 1067), de acordo com a catalogação do arquivo. As páginas manuscritas também receberam o carimbo daquela instituição. Há ainda registro de paginação a partir do verso da primeira folha, também a lápis. Algumas folhas receberam, além dos algarismos arábicos, paginação em algarismos romanos (iniciados em I na página 3 até a página 6). O papel utilizado como suporte para essa tradução é sem pautas e o trabalho não apresenta marcas de rasuras de qualquer espécie, configurando uma etapa préeditorial. De fato, a versão foi selecionada pelos netos do imperador para integrar a coletânea "Poesias (Originaes e Traducções) de S. M. O Senhor D. Pedro II”, publicada pela Tipografia do Correio Imperial em 1889.

Os outros dois conjuntos de manuscritos, arquivados no IHGB, pertencem à coleção "Baronesa de Loreto", e foram doadas à instituição em 1924. O primeiro deles foi redigido em papel sem laudas, tendo sido a frente e o verso da folha utilizados. São 14 páginas autógrafas. O papel apresenta a marca d'água com a inscrição Imperial Treasury de la rue, visível sobretudo no verso da primeira folha. Não há qualquer marca de movimento de escrita ou de criação. Possivelmente, D. Pedro II presenteou a Baronesa com seu trabalho, como era seu costume, daí o estado de escritura estar mais definitivo. Essa versão do trabalho difere daquela arquivada no Museu Imperial por conter um verso a mais, talvez esquecido quando da passagem a limpo da cópia arquivada no museu. A ausência do verso consta também na coletânea publicada em 1889, apontando qual das versões foi selecionada para o livro. Ambos os trabalhos datam, possivelmente, de meados de 1864. Vale lembrar que em novembro daquele mesmo ano Longfellow notificava o imperador do recebimento da tradução de seu poema e não poupava elogios ao monarca por sua tradução, afirmando terem as rimas duplas dado nova graça à

\footnotetext{
${ }^{4}$ Romanelli, Sergio; Stallaert, Christiane; MAFra, Adriano. Genética da tradução: o caso "liminal" de Dom Pedro II. In: FRÁGUAS, Alessandra Bettencourt F; RODRIGUES, Leandro Garcia (Eds.). Anuário do Museu Imperial: nova fase. Petrópolis: Museu Imperial, 2020, p. 165-190.
} 
narrativa ${ }^{5}$. Há, portanto, uma terceira cópia dessa tradução, mantida em algum dos arquivos de Longfellow nos Estados Unidos.

A segunda cópia da tradução imperial, inédita, data de 1887 e difere em alguns aspectos do trabalho anterior, especialmente na construção sintática e nas escolhas lexicais. Depois de 23 anos, D. Pedro II revisitou a obra de Longfellow e propôs nova tradução para o "Canto do Siciliano". Esta cópia totaliza 11 páginas autógrafas. Apesar de ser um material já passado a limpo, com certos cuidados em sua apresentação - o documento contém capa, foi redigido em folhas com pautas, o texto está dividido em estrofes e há uma espécie de "nota final" extraída de uma biografia de Longfellow publicada em $1882^{6}$-, o monarca ainda sugeriu modificações em dois versos. As intervenções foram anotadas a lápis nas entrelinhas do documento, sugerindo uma conformação ou ajuste pontual no texto tido como final. O documento autógrafo apresenta a inscrição no final da tradução: "(Traduzido por S. M. o Imperador) Tales of Way side Inn, by H. W. Longfellow. King Robert of Sicily". Na mesma página, no canto inferior esquerdo, está a data do documento: "Cópia entregue em abril de 1887, Petrópolis".

Os manuscritos que constituem as primeiras campanhas de escritura das duas traduções de D. Pedro II não foram localizados. Mesmo D. Pedro II sendo um conhecedor da língua inglesa desde muito cedo, a sua fixação pela obra de Longfellow $^{7}$ e conseguinte busca pelo aprimoramento de sua prática tradutória, além da espiralidade inerente ao processo criativo e as dificuldades de tradução de textos poéticos, certamente determinariam hesitações, cancelamentos, revisões e rasuras, o que nos sugere a existência de documentos anteriores (perdidos ou mesmo destruídos). Refinar o seu texto até chegar a fase "final" implicaria em análises e aprimoramentos, sobretudo quando sua tradução fosse apresentada aos seus interlocutores. Este foi o caso de "O Canto do Siciliano", como já dito anteriormente.

\section{Otexto fonte: The sicilian Tale}

Em 1864, D. Pedro havia feito a primeira tradução do poema "The Sicilian's Tale: King Robert of Sicily", sob o título "O Canto do Siciliano: El-Rei Roberto da Sicília". Presenteou Longfellow com sua tradução, que não poupou elogios e satisfação em recebê-la. "The Sicilian's Tale" foi publicado em Tales of a Wayside Inn (1863), edição que reúne uma coletânea de textos contados em uma taverna em Sudbury, Massachusetts. Narra a saga do Rei Roberto, "a jovem flor da Sicília", que em vésperas de São João, ouvia os monges entoarem o Magnificat. Repetido pelos monges como um refrão, Roberto ficou intrigado com a passagem: Deposuit potentes de sede, et

\footnotetext{
5 "I have had the honor of receiving your Majesty's beautiful version of "King Robert of Sicily" [...]. The translation is very faithful and very successful. The double rhymes give a new grace to the narrative, and the old Legend sounds very musical in the soft accent of the Portuguese" (MIMP - Maço 135 - Doc 6607 [D01 P01]/ [D01 P02]).

${ }^{6}$ Trata-se da obra Henry W. Longfellow: Biography, Anecdote, Letters, Cristicism, de William Sloane Kennedy. O trecho copiado informa como D. Pedro II teve acesso a obra de Longfellow, informando que o monarca ficou encantado, sobretudo, com a história do Rei Roberto de Sicília. O texto ainda informa sobre o recebimento da tradução do imperador por Longfellow, o qual julgou a tradução imperial como sendo a melhor frente a outras traduções em português.

${ }^{7}$ De acordo com Fletcher e Kidder, a admiração de D. Pedro II por Longfellow era latente. A primeira vez que Fletcher viu o monarca manifestar entusiasmo, feito uma criança que está prestes a ganhar um objeto desejado, foi ao ser questionado pelo imperador sobre o escritor. D. Pedro, em tom de lamento, teria dito que tem procurado por obras de Longfellow em todas as livrarias do Rio de Janeiro, sem sucesso. E continua: "I have a number of beautiful morceaux, but I wish the whole work; I admire him so very much”. FleTCHER, James C; KIDDER, D. P. Brazil and Brazilians: portrayed in historical and descriptive sketches. 9 ed. Boston: Little, Brown, and Company, 1879, p. 244.

${ }^{8}$ BAKER, Joan. Le Singe as le Signe: Serious Monkey Business in Robert of Sicily. The Profane Arts of Middle Ages, v. VI, n. 1, Spring 1997, p. 96-120.
} 
exaltavit humiles. Trata-se do Cântico de Maria, presente no Evangelho de Lucas (1, 46-55), que segundo a tradição, foi recitado pela Virgem Maria quando da visitação de sua prima Isabel. Sem entender aquela mensagem, indaga a um padre que está ao seu lado, que lhe dá a tradução: "Depôs dos tronos os poderosos, e elevou os humildes". Entediado e no auge de seu orgulho, Roberto afirma que tal regra só se aplica à Igreja, já que ninguém poderá tirá-lo de seu trono. Adormece com a monotonia do canto dos monges e acorda em noite escura, sozinho dentro da igreja e privado de suas galas. Percorre as galerias em meio à escuridão, esbraveja até chegar à corte e deparar-se com um grande banquete. Para a sua surpresa, o trono está ocupado por outro rei, um impostor com suas feições, porém com traços angelicais.

Roberto é recebido pelo Anjo, que o nomeia bobo da corte e ordena que seu cabelo seja cortado como o de um frade. $\mathrm{O}$ usurpador agora ocupava o seu trono: vestido como Roberto e fisicamente igual ao rei deposto, o impostor era aceito pelos súditos. Roberto é zombado, privado de seu conforto, se alimenta de restos de comida e tinha como única companhia um macaco vestido tal qual seu novo dono, porém mantém-se impassível, arrogante e desafiador durante três anos. Nesse período, o Papa Urbano solicita a presença dos irmãos Roberto e Valmundo, imperador Alemão, para as comemorações da Semana Santa. O evento se mostra como a última esperança de Roberto em desmascarar o rei farsante. Na Itália, na presença do Anjo e dos irmãos, Roberto se intitula rei. Apresenta-se vestido com uma capa feita de caldas de raposa, assim como seu mascote, para reivindicar seu trono. Para seu desespero, os irmãos não o reconhecem e ele é denunciado como louco. Passado o domingo de Páscoa, Roberto é chamado pelo Anjo, e a sós, reconhece seus erros. O Anjo então sorri, afirma não ser rei, revelando a sua real identidade e missão: castigar Roberto por seu orgulho excessivo. Ouve-se novamente o cântico dos monges vindo da capela. Roberto agora se encontra sozinho, vestido com os trajes suntuosos de outrora, reformado e restituído ao trono como um rei justo e temente a Deus. A sala é invadida pelos súditos, que o encontram "de joelhos absorto em tácita oração ${ }^{10}$.

A história do Rei Roberto da Sićlia tem suas raízes nas produções literárias do período denominado Middle English. De acordo com Powell ${ }^{11}$, o conto exemplar do monarca orgulhoso humilhado por Deus foi extremamente popular no final da Idade Média, considerando-se o número de manuscritos que se tem conhecimento: 9 deles, segundo o autor, com versões completas e outro com parte da história. Para Radulescu ${ }^{12}$, o fato de a história ter sido apreciada entre os séculos XIV e XV poderia ser explicado, em primeira instância, por seu teor moralizante e caráter didático, universalmente aceitos em todo o período. Contudo, a história vai além de uma lição moral e espiritual endereçada ao homem comum. O infortúnio de Roberto foi causado por seu orgulho e ele quem sofre a punição pelos seus atos. Logo, o texto aponta para além dos castigos divinos aplicados aos orgulhosos comuns, mas orienta os leitores a considerar aqueles governantes terrenos que se esqueceram do poder de Deus.

A narrativa de Roberto deixou de ser explorada por escritores modernos até atingir certo grau de popularidade novamente no século XIX, num movimento de retomada do interesse da literatura da época pela Idade Média. Classificada como romance devido aos seus elementos de cavalaria, a história foi adaptada por vários autores durante os oitocentos e parte do século XX, os quais deram novo vulto à narrativa. Longfellow,

\footnotetext{
9 A BíBlia SAgrada. Evangelho de Lucas (1: 52). Salt Lake City: Intellectual Reserve, Inc., 2015, p. 1554.

${ }^{10}$ AlCÂntara, Pedro de. Poesias (originais e traduções) de S. M. o Senhor D. Pedro II. Petrópolis: Typographia do "Correio Imperial", 1889 , p. 88.

${ }^{11}$ PowelL, Stephen D. Transforming the proud king transformed: Robert of Sicily. In: ALLAIRE, Gloria (Ed.). Modern Retellings of Chivalric Texts. London: Routledge Revivals, 1999, p. 67-82.

${ }^{12}$ Radulescu afirma que a história do "rei penitente" sobrevive em 10 manuscritos: cinco deles provavelmente datados do fim do século XIV e início do século XV, três de meados e dois do final do século XV. RADULESCU, Raluca L. Romance and its Contexts in Fifteenth-Century England: Politics, Piety and Penitence. Cambridge: D. S. Brewer, 2013.
} 
por exemplo, explorou o potencial narrativo do enredo em detrimento de sua moral didática. Por outro lado, assinala Powell, ${ }^{13}$ as intervenções do autor deram ao poema uma tônica humorística semelhante àquelas encontradas em certas versões medievais da obra. Para Steggle ${ }^{14}$, a versão em prosa de Leigh Hunt, publicada em 1847, foi utilizada por Longfellow como base de seu trabalho, que por sua vez, deu origem a inúmeras outras produções em prosa, dramatizações e versões ilustradas.

Sean Leahy ${ }^{15}$ afirma que o Sicilian Tale, cuja trama oferece uma moral de humildade e conversão cristã, se configura em uma história de transformação. A narrativa, segundo o autor, é impulsionada pelo foco de Longfellow na linguagem e na tradução, esta última protagonizada pelo clérigo no início da trama que traduz o Magnificat a pedido de Roberto. Longfellow retoma sua experiência como mediador entre linguagem, cultura e forma, a fim de explorar como esse conhecimento pode ser usado para influenciar o infeliz rei. A articulação entre os recursos da linguagem e o poder da tradução, basicamente o mote da história, foi capaz de criar elos inesperados e promover a transformação significativa indicada por Leahy ${ }^{16}$ : não fosse a intervenção do clérigo por meio da tradução, não haveria história. Os poderes conflitantes - religioso e real - se mesclam, tendo tradução e mediação uma função pedagógica, pois instruem Roberto acerca da natureza da tradição do clero, esta mantida e perpetuada através do texto bíblico.

\section{Análise preliminar das traduçóes imperiais: "O canto do siciliano"}

Conforme já citado, os manuscritos aqui analisados pertencem a coleções de instituições distintas. Até agora não se tem conhecimento de nenhum outro documento que registre os estágios de criação dessas traduções. Dos 216 versos presentes no original de Longfellow, as cópias da tradução de 1864 apresentam 213 e 212 versos. Na tradução de 1887, o monarca garantiu maior proximidade com a quantidade de versos constantes no original. São 215 versos, um a menos do montante que compõe o texto de partida. Do ponto de vista da forma, o tradutor mantém os versos rimados do texto, sendo o mesmo esquema de rimas proposto por Longfellow, ou seja, as rimas externas e emparelhadas. Os versos, em suma decassílabos no original, passam a agrupar variadas sílabas poéticas nas propostas do monarca, como o verso hendecassílabo, alexandrino e verso bárbaro.

Ao proceder a transcrição diplomática ${ }^{17}$ das cópias da primeira tradução do monarca, isto é, aquela empreendida em 1864, alguns pontos no nível microestrutural do texto devem ser destacados. Os manuscritos, que são produtos da mesma campanha de escritura e estão em fase de texto acabado, apresentam algumas divergências no que concerne à pontuação. Há alternâncias no uso de vírgulas, ponto e vírgula e ponto final. O uso de aspas também se mostra divergente nas duas versões do trabalho. Podemos suspeitar que a atenção do monarca, ao transcrever uma das cópias, esteve mais centrada no texto em si, como alguém que memoriza o verso e o transfere para o novo papel, usando a pontuação de maneira mais livre e intuitiva. No processo de copiar o texto, a distração fez com que um dos versos fosse excluído, fato que sugere que esse documento não passou por uma leitura final. Trata-se do terceiro verso da tradução, cuja ausência poderia ter sido notada em

\footnotetext{
${ }^{13}$ POWELL, Op. cit.

${ }^{14}$ STEGGLE, Matthew. Digital Humanities and the Lost Drama of Early Modern England: ten case studies. Farnham, U.K.: Ashgate Publishing, 2015.

${ }^{15}$ LEAHY, Sean. As One Who From a Volume Reads: A Study of the Long Narrative Poem in Nineteenth-Century America. 2019. Graduate College Dissertations and Theses. 1065. Avaiable at: https://scholarworks.uvm.edu/graddis/1065. Acesso em: 20 fev. 2020.

${ }^{16}$ Ibidem.

${ }^{17}$ A transcrição diplomática é pouco codificada, tenta se aproximar ao máximo das particularidades do documento e é de fácil leitura, além de se preocupar com a paginação autógrafa dos fólios. Cf. BIASI, Op. cit.
} 
uma revisão mais atenta, já que era no início do trabalho. O quadro abaixo apresenta alguns exemplos ilustrativos das diferenças de pontuação nos dois conjuntos de manuscritos. Apesar de não ter sido utilizada como texto final para a edição de 1889 , a cópia arquivada no IHGB, por estar completa, será considerada a principal neste estudo. Assim, o verso "esquecido" na cópia arquivada no Museu Imperial (e por conseguinte, na publicação de 1889) é exibido no primeiro exemplo:

\begin{tabular}{|c|c|c|}
\hline Verso & Tradução 1 IHGB (1864) & Cópia 1 MIMP (1864) \\
\hline 3 & $\begin{array}{l}\text { Com trage sumptuoso e galas } \\
\text { adornado, }\end{array}$ & -- \\
\hline 11 & $\begin{array}{l}\text { E diz a um douto padre junto } \\
\text { de seu lado, }\end{array}$ & $\begin{array}{l}\text { E diz a um douto padre junto } \\
\text { do seu lado: }\end{array}$ \\
\hline 17 & $\begin{array}{l}\text { "O padre, e na latina lingua } \\
\text { não s'entendem; }\end{array}$ & $\begin{array}{l}\text { "O padre, e na latina lingua } \\
\text { não s'entendem, }\end{array}$ \\
\hline 38 & $\begin{array}{l}\text { Sou El Rei! Tens receio?" } \\
\text { timido Sacrista }\end{array}$ & $\begin{array}{l}\text { Sou El-Rei! Tens receio? } \\
\text { timido Sacrista }\end{array}$ \\
\hline 98 & $\begin{array}{l}\text { Comem corceis áo pé, ás baias } \\
\text { amarrados. }\end{array}$ & $\begin{array}{l}\text { Comem corceis ao pé ás baias } \\
\text { amarrados, }\end{array}$ \\
\hline 206 & $\begin{array}{l}\text { Qual de corda singela, unisona } \\
\text { a vibrar, }\end{array}$ & $\begin{array}{l}\text { Qual de corda singela unisona } \\
\text { a vibrar, }\end{array}$ \\
\hline
\end{tabular}

Quadro 1: Diferenças na pontuação dos manuscritos de 1864.

Quando da preparação do texto para compor a coletânea publicada pelos netos do imperador em 1889 (reeditada em 1932), a pontuação do texto também sofreu modificações. Houve, no texto final, a supressão de vírgulas, a substituição de vírgulas por ponto e vírgula (ou o contrário), o acréscimo ou supressão de aspas, além da inserção ou substituição de vírgulas ou ponto e vírgulas por dois pontos no início do discurso direto, conforme quadro abaixo:

\begin{tabular}{|c|l|ll|}
\hline Verso & \multicolumn{1}{|c|}{ Cópia 1 MIMP(1864) } & \multicolumn{1}{|c|}{ Livro editado(1889) } \\
\hline 4 & $\begin{array}{l}\text { De muitos cavalleiros, nobres } \\
\text { rodeado, }\end{array}$ & $\begin{array}{l}\text { De muitos cavalleiros nobres } \\
\text { rodeado, }\end{array}$ \\
\hline 10 & $\begin{array}{l}\text { Começa a real cabeça apenas a } \\
\text { erguer; }\end{array}$ & $\begin{array}{l}\text { Começa a real cabeça apenas a } \\
\text { erguer, }\end{array}$ \\
\hline 12 & $\begin{array}{l}\text { "Que palavras são estas?" Bom } \\
\text { significado }\end{array}$ & $\begin{array}{l}\text { Que palavras são estas? Bom } \\
\text { significado }\end{array}$ & $\begin{array}{l}\text { Então El Rei Roberto altivo } \\
\text { resmonêa: }\end{array}$ \\
\hline 15 & $\begin{array}{l}\text { Então El Rei Roberto altivo } \\
\text { resmonêa }\end{array}$ & $\begin{array}{l}\text { Os convivas raivosos puxam das } \\
\text { espadas; }\end{array}$ & $\begin{array}{l}\text { Os convivas raivosos puxam das } \\
\text { espadas: }\end{array}$ \\
\hline
\end{tabular}

Quadro 2: Diferenças de pontuação entre manuscrito autógrafo (1864) e texto publicado (1889).

Uma característica bastante singular no conjunto de manuscritos da tradução de D. Pedro está na ortografia do português da época. Dado ao estado legível dos textos, as diferenças ortográficas registradas na época em comparação ao português atual não foram um dificultador durante a etapa de transcrição. Nota-se, nos manuscritos, que traços de base etimológica que regiam a grafia das palavras naquele período são recorrentes, como o caso das consoantes duplas, das consoantes mudas e dos alógrafos conotativos que denotam latinismo grafêmico $(<\mathrm{th}\rangle,\langle\mathrm{h}\rangle$ inicial ou interno, $\langle\mathrm{ch}\rangle,\langle\mathrm{ph}\rangle$ etc). Veja-se nos exemplos a seguir: 


\begin{tabular}{|c|c|}
\hline $\begin{array}{c}\text { Ortografia do português - } \\
\text { Século XIX }\end{array}$ & Ortografia atual do português \\
\hline Janelas & janelas \\
\hline thrôno/ throno & trono \\
\hline Céos & céus \\
\hline Schola & triunfante \\
\hline Triumphante & imensa \\
\hline Imensa & acordou \\
\hline Acordou & sono \\
\hline Somno & Christo \\
\hline Christo & aí \\
\hline Ahi & compreendem \\
\hline Compreendem & exceto \\
\hline Excepto & tateando \\
\hline Tacteando & Pedro \\
\hline
\end{tabular}

Quadro 3: Diferenças ortográficas no manuscrito de tradução de D. Pedro II (1864) e a ortografia atual do português.

No entanto, em alguns momentos, a escrita baseada em critérios etimológicos dos mesmos termos cede lugar a um registro mais fonético, tendência que culminou na sistematização ortográfica da língua prescrita no século posterior. O texto editado restitui a ortografia padrão da época, por tratar-se de uma publicação regida por normas editoriais. Alguns exemplos podem ser conferidos no quadro a seguir:

\begin{tabular}{|l|l|l|}
\hline \multicolumn{1}{|c|}{ Tradução 1 IHGB (1864) } & \multicolumn{1}{|c|}{ Cópia 1 MIMP (1864) } & \multicolumn{1}{|c|}{ Livro editado (1889) } \\
\hline Salas & Sallas & salas \\
\hline empirea & Empírea & empyrea \\
\hline Sacristão/ Sacrista & Sacristão/ Sacrista & $\begin{array}{l}\text { Sachristão/ } \\
\text { Sachrista }\end{array}$ \\
\hline Solenne & Solemne & solenne \\
\hline Choro & Choro & côro \\
\hline
\end{tabular}

Quadro 4: Diferenças ortográficas nos manuscritos de tradução de D. Pedro II (1864) e no livro publicado (1889).

No que concerne ao trabalho do monarca datado de 1887 , assinalo alguns pontos já aludidos. O primeiro deles refere-se aos aspectos formais da tradução proposta. Nessa segunda tradução, a quantidade de versos apresentada é maior que a da proposta anterior. Em termos de macroestrutura, houve também a preocupação do tradutor em separar o texto em estrofes, divisão essa semelhante a do texto de partida. O recurso, no entanto, não foi utilizado na primeira tradução. A métrica da tradução varia entre verso hendecassílabo e bárbaro, com certa frequência do alexandrino. As rimas, por seu turno, são consoantes, externas e emparelhadas.

No que concerne ao conteúdo, pode-se dizer que D. Pedro II modificou substancialmente a escolha vocabular de muitos versos, como é possível verificar abaixo: 


\begin{tabular}{|c|l|lc|}
\hline Verso & \multicolumn{1}{|c|}{ Tradução 1 IHGB (1864) } & \multicolumn{1}{|c|}{ Tradução 2 IHGB (1887) } \\
\hline 8 & $\begin{array}{l}\text { Deposuit potentes de Sede - e } \\
\text { o deão, }\end{array}$ & $\begin{array}{l}\text { Qual bordão, } \\
\text { "Deposuit potentes }\end{array}$ \\
\hline 24 & $\begin{array}{l}\text { Excepto um lampadario aqui; } \\
\text { ali mortiço, }\end{array}$ & $\begin{array}{l}\text { As lampadas sómente esparzem } \\
\text { brilho escasso, }\end{array}$ \\
\hline 37 & $\begin{array}{l}\text { De raiva e furia arfando El } \\
\text { Rei lhe diz: "Abri; }\end{array}$ & $\begin{array}{l}\text { Suffocando de raiva, o rei } \\
\text { lhe intíma: "Abri; }\end{array}$ \\
\hline 44 & $\begin{array}{l}\text { Que nem mesmo se volta, ou } \\
\text { Olha, nem lhe falla; }\end{array}$ & $\begin{array}{l}\text { Não se volta sequer, não } \\
\text { olha, nem boqueja, }\end{array}$ \\
\hline 51 & $\begin{array}{l}\text { Do ultrage e d'affronta } \\
\text { cheio o coração, }\end{array}$ & $\begin{array}{l}\text { Do mal e affronta ardendo } \\
\text { em desesperação, }\end{array}$ \\
\hline
\end{tabular}

Quadro 5: Diferenças lexicais nos versos das traduções de 1864 e 1887.

Num primeiro momento, poderíamos supor que D. Pedro II resolveu retraduzir o poema de Longfellow e testar novas figuras de construção e vocabulário em seu trabalho para aproximá-lo de uma tendência source-oriented, esta mais presente em suas traduções de línguas orientais. ${ }^{18}$ No entanto, ao confrontar a tradução com o texto fonte, nota-se que o empenho do monarca esteve, novamente, em manter a estrutura rimática do texto de partida, o que muitas vezes era possível a partir de recriações, de junção e reformulação do conteúdo de versos distintos e de inserção de elementos ausentes no original, práticas que já haviam sido a tônica do projeto anterior de tradução. No excerto abaixo, por exemplo, é possível conferir uma adição no texto de 1887 para assegurar a rima consoante em -undo:

\begin{tabular}{|c|c|l|l|}
\hline Verso & Tradução 1 IHGB (1864) & \multicolumn{1}{|c|}{ Tradução 2 IHGB (1887) } & \multicolumn{1}{c|}{ Texto fonte (1863) } \\
\hline 21 & $\begin{array}{l}\text { Embalado do canto } \\
\text { surdo e monotôno. }\end{array}$ & $\begin{array}{l}\text { Pelo psalmodear, } \\
\text { monotono } \\
\text { profundo, }\end{array}$ & $\begin{array}{l}\text { Lulled by } \\
\text { chant monotonous } \\
\text { and deep, }\end{array}$ \\
\hline 22 & -- & $\begin{array}{l}\text { Tornado } \\
\text { indifferente ás } \\
\text { impressões do } \\
\text { mundo. }\end{array}$ & \\
\hline
\end{tabular}

Quadro 6: Recriação na tradução de D. Pedro II de 1887.

Ao revisitar o texto de Longfellow, D. Pedro II pôde ainda restituir um verso ausente na tradução de 1864. Trata-se da fala do imperador Valmundo, que sugere que Roberto, tido como louco, seja o bobo da corte liderada pelo Anjo:

\footnotetext{
${ }^{18}$ Sobre a tradução de línguas orientais operada pelo monarca, ver: MAFRA, Adriano. O processo criativo de D. Pedro II na tradução do Hitopadeça. Tese (Doutorado em Estudos da Tradução). Programa de Pós-Graduação em Estudos da Tradução, Universidade Federal de Santa Catarina/Universiteit Antwerpen, Florianópolis, Antwerpen, 2015; e SoUZA, Rosane de. Edição genética da tradução das Mil e uma noites de d. Pedro II. Tese (Doutorado em Estudos da Tradução). Programa de PósGraduação em Estudos da Tradução, Universidade Federal de Santa Catarina, Florianópolis, 2015.
} 


\begin{tabular}{|c|c|l|l|}
\hline Verso & Tradução 1 IHGB (1864) & \multicolumn{1}{|c|}{ Tradução 2 IHGB (1887) } & \multicolumn{1}{c|}{ Texto fonte (1863) } \\
\hline \multirow{2}{*}{165} & -- & $\begin{array}{l}\text { Seja bobo da côrte } \\
\text { este desassisado! " }\end{array}$ & $\begin{array}{l}\text { To keep a madman } \\
\text { for thy Fool at } \\
\text { court! " }\end{array}$ \\
\hline
\end{tabular}

Quadro 7: Restituição de verso ausente na tradução do monarca de 1864.

Ainda sobre a escolha vocabular, no verso 60, por exemplo, a cognata perfume do final do verso foi traduzida por pivêtes, pouco usual na acepção de "perfume" atualmente, mas que manteve a rima com banquetes do verso anterior. O verbo trescalar, sinônimo de exalar, substituiu o verbo recender da proposta anterior. Note-se a mudança sintática entre o substantivo luz/luzes e a forma verbal/ adjetivo resplende/ resplendente:

\begin{tabular}{|c|l|l|l|}
\hline Verso & \multicolumn{1}{|c|}{ Tradução 1 IHGB (1864) } & Tradução 2 IHGB (1887) & \multicolumn{1}{c|}{ Texto fonte (1863) } \\
\hline \multirow{2}{*}{60} & $\begin{array}{l}\text { Que resplende de } \\
\text { luz; recende de } \\
\text { pivêtes. }\end{array}$ & $\begin{array}{l}\text { De luzes } \\
\text { resplendente, a } \\
\text { trescalar pivêtes. }\end{array}$ & $\begin{array}{l}\text { Blazing with } \\
\text { ligreathing with } \\
\text { perfume. }\end{array}$ \\
\hline
\end{tabular}

Quadro 8: Diferenças sintáticas nas traduções de 1864 e 1887.

No verso 145, D. Pedro insere o adjetivo pachorrento, inexistente no texto de Longfellow, para garantir a manutenção da rima. Na versão de 1864, o advérbio demurely, que indica o comportamento tímido do macaco, foi substituído pelo adjetivo grave, sugerindo um aspecto sério ao mascote de Roberto:

\begin{tabular}{|c|l|l|l|}
\hline Verso & Tradução 1 IHGB (1864) & Tradução 2 IHGB (1887) & \multicolumn{1}{|c|}{ Texto fonte (1863) } \\
\hline \multirow{3}{*}{145} & $\begin{array}{l}\text { Grave e solenne o } \\
\text { môno atraz d'elle } \\
\text { montando, }\end{array}$ & $\begin{array}{l}\text { Atraz d'elle } \\
\text { trepado o mono } \\
\text { pachorrento, }\end{array}$ & $\begin{array}{l}\text { The solemn ape } \\
\text { demurely perched } \\
\text { behind, }\end{array}$ \\
\hline
\end{tabular}

Quadro 9: Diferença de escolha vocabular nas traduções de 1864 e 1887.

Apesar de ser uma versão passada a limpo e com características de um texto já definitivo ou final, a tradução de 1887 apresenta duas ligeiras intervenções, apenas conformações estéticas pontuais que certamente seriam consideradas caso fosse esse o trabalho escolhido para ser publicado. No primeiro trecho, além da figura sintática caracterizada pela inversão entre verbo e substantivo (hipérbato), a variação ocorre entre os tempos verbais presente e pretérito perfeito do indicativo do verbo sumir.

\begin{tabular}{|c|c|}
\hline Verso & Tradução 2 IHGB (1887) \\
\hline & E some-se da vista, \\
47 & E da vista sumiu-se, espectro sobrehumano. \\
\hline
\end{tabular}

Quadro 10: Revisão textual proposta por D. Pedro II na tradução de 1887.

No verso 114, a busca por aprimoramentos está na revisão do particípio passado do verbo raspar e da conjunção como, que indica uma comparação. Na adição sugerida por D. Pedro, o 
substantivo cercilho aparece como possibilidade, antecedido pela preposição com. A ideia de comparação, assim, é apagada:

\begin{tabular}{|c|c|}
\hline Verso & Tradução 2 IHGB (1887) \\
\hline 114 & $\begin{array}{c}\text { Com cercilho de frade, } \\
\text { Raspado como úm frade, alvo dos vituperios }\end{array}$ \\
\hline
\end{tabular}

Quadro 11: Revisão textual proposta por D. Pedro II na tradução de 1887.

Por fim, a análise preliminar das duas traduções de D. Pedro II nos faz refletir sobre qual das versões do trabalho o autor desejaria, de fato, publicar: a de 1864, elogiada pelo autor do original; ou a de 1887, refeita após mais de duas décadas do primeiro movimento de criação? Talvez se D. Pedro tivesse participado do processo editorial de seleção e organização dos textos - lembrando que a edição de 1889 foi uma homenagem dos seus netos -, o "Canto do Siciliano" de 1887 poderia ter figurado no projeto editorial em questão. De todo modo, é importante destacar mais uma vez o papel dessas traduções no ousado projeto político de construir uma identidade para a jovem nação brasileira. Solidificar as bases da "cidade letrada ${ }^{19}$ " e obter junto ao círculo intelectual internacional a legitimação e o reconhecimento do país enquanto uma nação moderna e culturalmente independente eram objetivos perseguidos incessantemente pelo monarca.

\section{o "imperador democrata" nos Estados Unidos e o encontro com Longfellow}

O primeiro encontro de D. Pedro e Henry Longfellow (1807 - 1882) se deu em solo norte-americano em 1876, em decorrência da segunda viagem do imperador ao exterior. A amizade entre eles, no entanto, começou a se consolidar no final da década de 1850, graças ao empenho do Reverendo James Cooley Fletcher. Após um período de missões no Brasil, Fletcher fixou residência em Massachusetts, centro da vida intelectual americana da época graças ao prestígio da Universidade de Harvard. De acordo com James, "D. Pedro II sentiu o fulgor dessa irradiação [cultural de Cambridge] pela leitura constante de livros dos poetas e cientistas da Nova Inglaterra que Fletcher lhe enviava ${ }^{20 "}$. O reverendo americano aproximou D. Pedro de um seleto grupo de intelectuais: os poetas Henry Longfellow e John Whittier, além do naturalista Louis Agassiz, figuras centrais nas primeiras trocas culturais entre Brasil e Estados Unidos. A história dessas relações é quase que completamente contada pelos próprios signatários em 130 missivas trocadas entre eles por décadas. A troca epistolar entre a elite intelectual norte americana e o monarca relacionam-se com os mais variados assuntos, especialmente com a literatura e as ciências naturais. Os contextos político e social das duas nações também são assuntos de pauta, mas aparecem subordinados pelos signatários ao interesse de D. Pedro por poesia, astronomia, geologia e ciências biológicas ${ }^{21}$.

Além de se corresponder com Longfellow, D. Pedro II também recebia informações acerca do poeta e suas produções por intermédio dos demais interlocutores, especialmente de Fletcher. Em agosto de 1864, James Fletcher relatava estar duplamente honrado por ter lido a excelente tradução de D. Pedro II e por ser o responsável por entregá-la a Longfellow. Em carta de abril de 1865, o reverendo informava o monarca sobre o

\footnotetext{
${ }^{19}$ RAMA, Ángel. La ciudad letrada. Montevideo: Arca, 1998.

${ }^{20}$ JAMES, David. O imperador do Brasil e os seus amigos da Nova Inglaterra. Tradução Mário José da Silva Cruz e Lourenço Luiz Lacombe. Petrópolis: Museu Imperial; Ministério da Educação e Saúde, 1952, p. 39.

${ }^{21}$ Ibidem.
} 
julgamento de Longfellow da tradução recebida em Cambridge: "Sr. Longfellow disse-me que a tradução de Sua Majestade do 'Rei Roberto da Sicília' era muito mais apropriada e fiel que a de [Miguel Maria] Lisboa ${ }^{22 ” . ~ E m ~}$ janeiro do ano seguinte, Fletcher encaminhava poemas de Whittier a D. Pedro e dava novas sobre Longfellow, dizendo que o poeta o aguardava para conversar sobre o Brasil e sobre o imperador: "Sua Majestade é um preferido do Sr. Longfellow ${ }^{23}$. Agassiz, no mesmo ano, procurava obter de seus amigos americanos no Rio, notícias de Longfellow para transmitir ao imperador. Em 1867, D. Pedro II recebia, por intermédio de Agassiz, o primeiro volume da tradução da "Divina Comédia" realizada pelo poeta americano.

A gradual aproximação entre a corte de D. Pedro II e os Estados Unidos culminou na inserção do país no roteiro da segunda viagem do monarca em 1876. Louis Agassiz, maior incentivador da visita de D. Pedro II aos Estados Unidos, na época um jovem país republicano, previu uma marcha triunfal de um extremo a outro da nação com a presença do soberano ${ }^{24}$. Agassiz faleceu em 1873, três anos antes da visita do ilustre amigo em território americano. Sua esposa, Elizabeth Cabot Agassiz, com quem D. Pedro também se correspondia, solicitou a Longfellow sugestões sobre como receber o imperador no jantar que marcaria o primeiro encontro do chefe de estado e do prestigiado poeta ${ }^{25}$.

Em fins de março de 1876, D. Pedro II deixava o país pela segunda vez na vida. Zarpando do Rio de Janeiro, alguns passageiros, em suma americanos, viajaram a bordo do vapor Hevelius em companhia da comitiva imperial sob o comando do capitão Markwell. Além deles, o repórter do jornal New York Herald, James O'Kelly, fez a cobertura da viagem desde o embarque no Rio, agraciando os leitores daquele periódico com as mais variadas crônicas do seu convívio com a Casa Imperial Brasileira. A imagem do soberano cede lugar a do cidadão comum, avesso as suntuosidades e rituais maçantes inerentes ao cargo que ocupava. D. Pedro II teria, inclusive, solicitado à filha que só o dirigisse os "telegramas indispensáveis sobre negócios ${ }^{26 ”}$.

Durante o período em alto mar, desenvolveu-se entre Pedro e O'Kelly uma relação de cumplicidade. Nas muitas conversas a bordo do Hevelius, o jornalista registra a ansiedade do imperador em conhecer americanos ilustres e a recusa às formalidades ou recepções oficiais: "E Longfellow, onde está? Tive pena que ele não aceitasse escrever a Ode do Centenário". E continua mais adiante: "[Longfellow] tem-me escrito algumas vezes. Traduzi alguns dos seus poemas em português e enviei-lhe. Procurei também interessá-lo na tradução dos Lusíadas. Poderia fazê-la, que eu saiba, melhor do que ninguém ${ }^{27 ”}$. Durante a viagem, D. Pedro II não se desfez de velhos hábitos. Lia muito e tinha aulas de sânscrito com Henning, seu professor de línguas orientais no período. Evitava discutir política, mas conversava livremente sobre artes e ciências. Segundo Carvalho ${ }^{28}$, o imperador quis traduzir o hino americano Star-Spangled Banner, mas "para embaraço geral, nenhum dos passageiros americanos sabia a letra".

D. Pedro II aportou em Nova Iorque em 15 de abril de 1876. Antes mesmo de pisar em terra firme, pergunta por Longfellow e pelo General William T. Sherman, notável por comandar com sucesso as tropas sulistas na Guerra Civil americana. Para a frustração geral das autoridades presentes, D. Pedro dispensou as

\footnotetext{
22 “Mr. Longfellow told me that Your Majesty's translation of 'King Robert of Sicily' was much more felicitous and faithful than that of [Miguel Maria] Lisboa" (Ibidem, p. 70).

23 "Your Majesty is a favorite of Mr. Longfellow" (Ibidem, p. 97).

${ }^{24}$ Carvalho, José Murilo. D. Pedro II: ser ou não ser. Coordenação: Elio Gaspari e Lilia M. Schwarcz. São Paulo: Companhia das Letras, 2007; Guimarães, Argeu. D. Pedro II nos Estados Unidos. Rio de Janeiro: Ed. Civilização Brasileira, 1961.

${ }^{25}$ JAMES, Op. cit.

${ }^{26}$ BARMAN, Roderick J. O imperador cidadão e a construção do Brasil. Tradução Sonia Midori Yamamoto. São Paulo: UNESP, 2010, p. 391.

${ }^{27}$ GUIMARÃES, Op. cit., p. 107.

${ }^{28}$ CARVAlHO, Op. cit., p. 163.
} 
pompas cerimoniais, explicando que o imperador ficara no Brasil e que ali estava apenas o viajante Pedro d'Alcântara. Lyra ${ }^{29}$ parece sintetizar bem a figura do cidadão Pedro:

longe de aparecer ali apertado num vistoso fardão, pesado de condecorações [...] foi visto percorrendo a pé as ruas da cidade, com a roupa burguesa de toda a gente, um modesto chapéu de feltro na mão, simples e atencioso, e o indefectível guarda chuva debaixo do braço.

D. Pedro ocupou os dias nos Estados Unidos com visitas a escolas, museus, academias militares, fábricas, sinagogas, igrejas, delegacias de polícia, instituições governamentais e bibliotecas; fazendo uma verdadeira corrida aos quatro cantos do continente americano, como prevera Agassiz. As rápidas paradas serviam para satisfazer a sua curiosidade sobre o funcionamento e organização dos estabelecimentos, com a intenção de trazer de lá tudo o que pudesse contribuir para o progresso do império. James O’Kelly, aproveitando a popularidade do monarca em seu país, não poupou críticas ao governo: "quando voltar a pátria, saberá mais dos Estados Unidos do que dois terços do Congresso ${ }^{30 "}$.

Outro interesse de D. Pedro era visitar a Exposição Universal em comemoração ao centenário da independência americana, realizada em Filadélfia no dia 10 de maio. A inauguração da exposição contou com a presença do então presidente Ulysses Grant e do imperador, terminando no pavilhão de máquinas onde juntos acionaram a Corliss Steam Engine, fornecendo energia para 8 mil equipamentos da exposição. Para Barman ${ }^{31}$, "seu modo amistoso e seu genuíno interesse pela exposição facilmente fizeram com que D. Pedro II ofuscasse o presidente Grant". No dia seguinte, D. Pedro jantaria na casa do ministro inglês Edward Thornton, registrando em seu diário o pesar pelo não comparecimento do poeta Longfellow na ocasião. O encontro dos dois ficaria adiado por mais um mês, de acordo com as anotações no mesmo diário:

\section{9 de junho de 1876}

Estava almoçando quando chegou Agassiz filho com quem muito simpatizei. Ficou combinada a ida a Cambridge - amanhã. Passo lá todo o dia. Almoço com os Agassiz e janto com Longfellow $^{32}$.

Nas anotações do dia seguinte em seu diário, D. Pedro II, de maneira breve, relata o encontro na casa da família Agassiz: "Às 8 1/2 fui a Cambridge. Chega-se por uma rua de cottages à casa de Agassiz. Almocei aí com Longfellow que logo conheci pela fotografia [...] De Longfellow não é preciso falar ${ }^{33}$ ”. Elizabeth Agassiz registrou algumas de suas impressões sobre a participação de D. Pedro no evento: "reunimos algumas pessoas para conhecê-lo, sendo que o convidado de honra foi Longfellow e foi para mim um prazer que se tivessem encontrado sob nosso teto ${ }^{34 ”}$. À noite, a recepção seria na casa de Longfellow:

Jantei com Longfellow. [...] Longfellow estava também docemente espirituoso e gostei das 3 filhas que também jantaram, não estando Mme. Agassiz, nem Lowell, Liman, Lawrence presidente do Harvard-College, Elliot e Pourtalés. Mas julgo-os todos amigos ${ }^{35}$.

\footnotetext{
${ }^{29}$ LYRA, Heitor. História de D. Pedro II: Fastígio (1870-1880). São Paulo: Companhia Editora Nacional, 1939, p. 372.

${ }^{30}$ GUIMARÃES, Op. cit., p. 107.

${ }^{31}$ BARMAN, Op. cit., p. 396.

32 AlCÂNTARA, Pedro de. Diário do Imperador D. Pedro II. Organização Begonha Bediaga. Petrópolis: Museu Imperial, 1999, p. 309, grifos do autor.

${ }^{33}$ Ibidem, p. 310.

${ }^{34}$ JAMES, Op. cit., p. 259.

${ }^{35}$ ALCÂNTARA, Op. cit., p. 311.
} 
E continua: "Longfellow deu-me dois livros de sua livraria e depois do jantar passeamos bastante na varanda do lado da casa fazendo-me ele bastantes perguntas sobre o Brasi ${ }^{36 ”}$. Na hora de partir rumo a Europa, segundo Guimarães ${ }^{37}$, D. Pedro teria convidado o velho amigo a visitar o Brasil. Longfellow teria prometido e relatou no dia seguinte em seu diário o quanto estimaria poder corresponder ao convite de Sua Majestade, porém a idade avançada não lhe permitiria tal aventura. Viu no soberano a encarnação da mocidade eterna e um ousado Harum-al-Rachid dando a volta ao mundo disfarçado de peregrino. "É um nobre, cordial, alegre e de opiniões muito liberais $^{38,}$, registra Longfellow em seu diário.

\section{Conclusões}

O presente artigo objetivou apresentar uma análise preliminar de três grupos de manuscritos tradutórios do imperador Pedro II. Trata-se de duas traduções do poema "The Sicilian Tale: King Robert of Sicily", cronologicamente separadas por um período de 23 anos: a primeira delas, com duas cópias em estado de manuscrito pré-definitivo, não apresenta rasuras ou qualquer vestígio de produção. Os documentos autógrafos datam de 1864 e são produtos do mesmo processo escritural. Uma das cópias compôs a coletânea de poesias e traduções do imperador publicada em 1889. A segunda tradução, inédita, é de 1887, e apesar de também estarem os manuscritos em uma fase avançada de escritura, o monarca sugeriu ligeiras modificações em duas passagens de seu trabalho. São os únicos indícios do complexo processo de criação materializados no documento, já que não localizamos cópias anteriores desses trabalhos. No entanto, considerando as pesquisas acerca do fazer tradutório de D. Pedro II $^{39}$, muito possivelmente as etapas precedentes que culminaram nessas produções foram de intenso jorro de ideias, leituras, cancelamentos, inserções e modificações de natureza variada. Essa incompletude documental nos permite apenas a entrever parte do processo que resultou nas traduções analisadas. Os diários e as cartas endereçadas ao autor traduzido e aos integrantes do círculo social do poeta, nesse caso, oferecem alguns dados significativos que ajudam a compreender o contexto de produção e, principalmente, a circulação do texto traduzido.

Sendo D. Pedro II um típico arquétipo do homem letrado do século XIX, ele conhecia com propriedade e se valia dos mecanismos de intercâmbio entre o centro letrado - neste caso, os Estados Unidos, centro do polissistema cultural de prestígio - e a sua corte com sede no Rio de Janeiro. A partir do contato com James Fletcher, o "cupido" na relação de amor entre D. Pedro II e os Estados Unidos ${ }^{40}$, o monarca foi inserido no universo intelectual e literário norte-americano. Das mãos do próprio Fletcher, D. Pedro recebeu algumas produções de Longfellow, inclusive a coletânea onde consta o poema original por ele traduzido. Confiou ao missionário a entrega de sua tradução do "Canto do Siciliano" ao poeta, que em carta de agradecimento teceu elogios ao trabalho do imperador. Aliás, o envio de suas traduções aos autores dos originais - como também ocorreu com o norte americano John Whittier - ou a terceiros - como a Baronesa de Loreto -, se constitui em um traço muito característico em D. Pedro, isto é, a necessidade de interação tendo a prática tradutória como pano de fundo para a sua diplomacia cultural. Em muitos casos, o insight criativo do monarca para a sua atividade tradutória é despertado com o recebimento de um texto - logo convertido em uma tradução em potencial -, seja pelas mãos do próprio escritor, seja por intermédio de amigos e pessoas próximas ao seu círculo. O elo se fecha

\footnotetext{
${ }^{36}$ Ibidem.

${ }^{37}$ GUIMARÃES, Op. cit.

${ }^{38}$ JAMES, Op. cit., p. 253.

${ }^{39}$ No site do NUPROC (http://nuproc.cce.ufsc.br/trabalhosacad.html), o leitor interessado no labor tradutório de D. Pedro II encontrará as pesquisas desenvolvidas no âmbito do projeto "D. Pedro II tradutor: análise do processo criativo".

${ }^{40}$ CarvalHo, Op. cit., p. 159.
} 
quase sempre com o envio da tradução à parte interessada, consolidando assim a tradução como uma manifestação de sociabilidade, um canal privilegiado para comungar de certas ideias e do mesmo interesse estético de seus interlocutores.

Um ponto interessante sobre a tradução da obra de Longfellow está no fato de D. Pedro II ter proposto uma segunda versão do poema "The Sicilian Tale". Por ora, não encontrei testemunhos documentais sobre as motivações do monarca em retraduzir o texto, mas alguns elementos podem ser considerados. A primeira tradução foi feita antes mesmo de D. Pedro II ter conhecido Longfellow. Suas preocupações com a gestão do império ocupavam grande parte de sua rotina e ele só iniciaria suas viagens e interlocuções presenciais com a intelectualidade europeia e americana anos mais tarde. A segunda é marcada por duas situações que podem ter determinado sua produção: a visita a Longfellow nos Estados Unidos, evento que teve grande significado na vida de Pedro d'Alcântara, pois o imperador acompanhava o trabalho do escritor de longa data; e a morte do autor no início da década de 1880 , profundamente lamentada pelo monarca ${ }^{41}$.

Finalmente, os manuscritos de 1887 ainda nos fazem refletir sobre outro aspecto, no que diz respeito a publicação da tradução e conseguinte fixação do texto final. Estaria D. Pedro II satisfeito com o resultado obtido em seu trabalho de 1864 ao ponto de querer vê-lo publicado? A tradução publicada, incompleta, expressaria de fato sua vontade autoral? Uma pesquisa mais aprofundada talvez possa elucidar quais as motivações por detrás desse trabalho e se a obra configura sua aspiração autoral. Os dois projetos de criação, no entanto, corroboram aos pilares da crítica genética, pois representam processos complexos, instáveis e singulares, evidenciando o texto em progressão para compreender os circuitos e conexões que foram se estabelecendo durante a gênese artística das obras. Com os recursos de análise oferecidos pela crítica genética, pode-se remontar ao processo de criação do autor Pedro d'Alcântara, descortinar uma série de apontamentos acerca do contexto histórico e cultural de produção, além de promover uma revisão crítica de seu trabalho a partir dos manuscritos e dos documentos a ele de alguma maneira associados, o que não seria possível ao enfocar simplesmente o texto tido como final.

\section{Referencias bibliográficas}

A BíBLIA SAGRADA. Evangelho de Lucas (1: 52). Salt Lake City: Intellectual Reserve, Inc., 2015.

AlCÂnTARA, Pedro de. Diário do Imperador D. Pedro II. Organização Begonha Bediaga. Petrópolis: Museu Imperial, 1999.

Poesias (originais e traduções) de S. M. o Senhor D. Pedro II. Petrópolis: Typographia do "Correio Imperial”, 1889.

BAKER, Joan. Le Singe as le Signe: Serious Monkey Business in Robert of Sicily. The Profane Arts of Middle Ages, v. VI, n. 1, Spring 1997, p. 96-120.

BARMAN, Roderick J. O imperador cidadão e a construção do Brasil. Tradução Sonia Midori Yamamoto. São Paulo: UNESP, 2010.

BELLEMIN-NOËL, Jean. Reproduzir o manuscrito, apresentar os rascunhos, estabelecer um prototexto. Manuscrítica: Revista de Crítica Genética. São Paulo, APML, n. 4, 1993, p. 127-161.

BIASI, Pierre-Marc de. A genética dos textos. Tradução Marie-Hélène Paret Passos. Porto Alegre: EDIPUCRS, 2010.

\footnotetext{
${ }^{41}$ Em maio de 1882, D. Pedro II escrevia a Elizabeth Agassiz: "La mort de Longfellow est profondément regretté (sic) surtout par ceux qui ont eu le bonheur de le connaître et lui ont dû tant de témoignages de sympathie” (JAMES, Op. cit., p. 280).
} 
A crítica genética. In: BERGEZ, Daniel et al. Métodos críticos para a análise literária. Tradução Olinda Maria Rodrigues Prata. São Paulo: Martins Fontes, 1997.

CARVAlHo, José Murilo. D. Pedro II: ser ou não ser. Coordenação Elio Gaspari e Lilia M. Schwarcz. São Paulo: Companhia das Letras, 2007.

Even-Zohar, Itamar. Polysystem Theory. Poetics Today. International Journal for Teory and Analysis of Literature and Communication, v. 11, n. 1, Spring 1990.

FAIQ, Said. The cultural salad in/of translation. In: FAIQ, Said (Ed.). Cultures in Dialogue: a translational perspective. Antwerp; Apeldoorn: Garant, 2010, p. 13-22.

FLETCHER, James C.; KIDDER, D. P. Brazil and Brazilians: portrayed in historical and descriptive sketches. 9 ed. Boston: Little, Brown, and Company, 1879.

GentZler, Edwin. Teorias contemporâneas da tradução. Tradução Marcos Malvezzi. São Paulo: Madras, 2009.

GRÉSILLON, Almuth. Elementos de crítica genética: ler os manuscritos modernos. Supervisão da tradução Reulliard. Porto Alegre: Editora UFRGS, 2007.

GUIMARÃES, Argeu. D. Pedro II nos Estados Unidos. Rio de Janeiro: Ed. Civilização Brasileira, 1961.

HERMANS, Theo. Translation in Systems. Descriptive and System oriented Approaches Explained. Manchester: St. Jerome Publishing, 1999.

JAMES, David. O imperador do Brasil e os seus amigos da Nova Inglaterra. Tradução Mário José da Silva Cruz e Lourenço Luiz Lacombe. Petrópolis: Museu Imperial; Ministério da Educação e Saúde, 1952.

LAMBERT, José; GoRP, Hendrik van. On describing translations. In: HERMANS, Theo. (Ed.). The Manipulation of Literature. Studies in Literary Translation. London \& Sidney, Croom Helm, 1985, p. 42-53.

LEAHY, Sean. As One Who From a Volume Reads: A Study of the Long Narrative Poem in Nineteenth-Century America. 2019. Graduate College Dissertations and Theses. 1065. Avaiable at: https://scholarworks.uvm.edu/graddis/1065. Acesso em: 20 fev. 2020.

LEFEVERE, André. Translation, Rewriting \& the Manipulation of Literary Fame. London: Routledge, 1992.

LYRA, Heitor. História de D. Pedro II: Fastígio (1870-1880). São Paulo: Companhia Editora Nacional, 1939.

LONGFELLOW, Henry Wadsworth. Tales of a Wayside Inn. Boston: Ticknor and Fields, 1863.

MAfRA, Adriano. O processo criativo de D. Pedro II na tradução do Hitopadeça. Tese (Doutorado em Estudos da Tradução) - Programa de Pós-Graduação em Estudos da Tradução, Universidade Federal de Santa Catarina, Universiteit Antwerpen, Florianópolis, Antuérpia, 2015.

POWELL, Stephen D. Transforming the proud king transformed: Robert of Sicily. In: ALLAIRE, Gloria (Ed.). Modern Retellings of Chivalric Texts. London: Routledge Revivals, 1999.

Radulescu, Raluca L. Romance and its Contexts in Fifteenth-Century England: Politics, Piety and Penitence. Cambridge: D. S. Brewer, 2013.

RAMA, Ángel. La ciudad letrada. Montevideo: Arca, 1998.

Romanelli, Sergio; Stallaert, Christiane; Mafra, Adriano. Genética da tradução: o caso "liminal" de Dom Pedro II. In: FRÁGUAS, Alessandra Bettencourt F.; RODRIGUES, Leandro Garcia (Eds.). Anuário do Museu Imperial: nova fase. Petrópolis: Museu Imperial, 2020, p. 165-190.

SouZA, Rosane de. Edição genética da tradução das Mil e uma noites de d. Pedro II. Tese (Doutorado em Estudos da Tradução). Programa de Pós-Graduação em Estudos da Tradução, Universidade Federal de Santa Catarina, Florianópolis, 2015.

STEGGLE, Matthew. Digital Humanities and the Lost Drama of Early Modern England: ten case studies. Farnham, U.K.: Ashgate Publishing, 2015. 
TOURY, Gideon. Descriptive Translation Studies and Beyond. Amsterdam; Philadelphia: John Benjamins Publishing Company, 1995.

Willemart, Philippe. Universo da criação literária: crítica genética, crítica pós-moderna? São Paulo: Edusp, 1993.

Recebido em: 30 de abril de 2020

Aceito em: 03 de julho de 2020 